\title{
Discussion about Men's Clothing of Neutral Phenomenon
}

\author{
Yimiao $\mathrm{Tu}^{1} \&$ Yue $\mathrm{Hu}^{1}$ \\ ${ }^{1}$ Shanghai University of Engineering Science, China \\ Correspondence: Yimiao Tu, No. 333, Longteng Road, Songjiang District, Shanghai City, China
}

Received: September 23, 2015

Accepted: October 12, 2015

Online Published: October 19, 2015

doi:10.5430/jbar.v4n2p52

URL: http://dx.doi.org/10.5430/jbar.v4n2p52

\begin{abstract}
Men's wear has shown a developing tendency toward neutralization, which is a product of the wind. In the early 18th century, it had its tendency. Now it appears again with some reasons. This paper shows us some aspects of definition, origin, development of the phenomenon of neutralization. What's more, the paper analyzes the reasons for men's neutral garment deeply. It explains the new characteristics with the focus of the current new performance of the neutralization.
\end{abstract}

Keywords: Neutralization, Definition, Origin, Reason, New characteristics

\section{Introduction}

Nowadays, social diversification has deepened gradually, the growing emergence of new things, the enhancement of people's acceptance and fashion taste. Some men who always have a low-key attitude towards dressing up are beginning to highlight the clothing and dressing up for their charming and uniqueness. Therefore, men's wear of neutralization also arises. Men's clothing like that does not make men become sissy or bizarre. On the contrary, it can expand the range of the choice of men's clothing. As a result, it becomes more innovative, more diversified and more personalized.

In the past, people's idea on the wearing style of neutralization is the result of sexual orientation. There is no denying that GAY culture has played a great role in the process of neutralization of men's clothing. But today, the male neutral clothing is not the problem of sexual orientation, it dues to personal fashion, taste, or showing one's charm most likely. Reflecting their own personalities, uniqueness, difference. Clothing is a manifestation of a refined, sophisticated life. Men are more likely to pay attention to dressing like women, which is to express themselves, attract others easily. Therefore, men's clothing is becoming more broad, the neutralization is just a developing tendency.

The definition of men's wear of neutralization

Neutralization is not equal to gender inversion, it conveys a special situation, temperament and beauty of no difference in gender.

Clothing neutralization in which there is no obvious characteristics can be used for discriminating gender.

Men's wear of neutralization refers to the commonly used to represent female temperament characteristics of the technique used in men's wear, not a single emphasis on men's characteristics of masculine and strength, but to a certain extent, weakening it, making men's performance towards the phenomenon of blurry gender.

\section{The origin of men's wear of neutralization}

Men's clothing of neutralization is not a special phenomenon in current society. In the east, during the period of Wei Jin southern and northern dynasties, the early male love to paint something on face, dress bright clothing. People always focus on dressing up with enthusiasm from many ancient books. In the west, ancient Rome, we have a false visual sense in men's trousers like skirts. The early 18th century European Louis phase at a quarter, men have a strong feeling in terms of dressing up. They paint, well-dressed, no less than women. Western famous peacock revolution, is the famous event that leading the new men's clothing fashion, is the ture proof of the neutralization on men's road. Since the eighteenth century, men's clothing of neutralization with the rise and fall of the feminist movement is in good condition or in bad condition, never disappear. 


\section{The analysis of the causes of men's wear of neutralization}

1) The men's own individual reasons. Like women, men like to look more handsome so as to attract the optosipe sex . Women are no longer the only people who attach great importance to the appearance, men also gradually become a group that has a variety of aesthetic orientation, in many industries, such as art, dancing, film and television, fashion and so on. Men have the requirements of its image, their external image and dressing very seriously. Neutral costumes for the purpose of self-interest, breaking the bondage of the body clothing shape, simplifying the complex classification of clothing, the pursuit of natural simplicity, abandoning a fancy, becoming the representative of pragmatism. With the gimmick of women's clothing design, the men's clothing design with plenty of freedom and also making men enjoy the pleasure of fashion through the gorgeous dress, while men's implicit inner beauty also fully reveal through this kind of clothing. They do not reject the element of a few feminine dressing to show their aesthetic personalities, or use the "Male perfume" and "Male cosmetics", these will be more conducive to launch their charm.

2) The changes of social status. In terms of the whole social environment, economic development makes the role and social status of men and women in the social change, social progress leads to the more equal status for men and women. We don't need pure manual labor to earn food to survive today, social productivity of the physical strength has not fully relied on the basic tools, but begin to rely on science and technology, knowledge, ability and so on. Many mental labor jobs for gender requirements are more and more fuzzy, men and women's work is basically the same intensity, gender is retreated to a secondary position, to determine your position and salary is your performance, then has the so-called "Neutral professional people", in this environment, the social competition law has been more equal, no bias. In this context, the male no longer in the workplace has the relative monopoly status as usual. Men and women are increasingly close, complementary, "gender" boundary between men and women is becoming more and more dark. In life, on the other hand, the man begin to help take on only women's work in the past, such as raising children, guiding the house, they also can hold the children in the street or ferry their children to school, mall shopping no longer is a woman's patent. Man as a housewife has become a social fashion. In addition, the development of the feminist movement also affected the social attitude towards life and career choice for both men and women. Therefore, with the change of the social roles for men and women and the change of the respective force in society, the authority of the traditional social roles and sex is under the impact of the change of social production mode, men are weakened, becoming increasingly diversified. The emergence of this phenomenon has played a subtle influence on clothing trend, give neuter clothing more development space. This concept of Men's wear of neutralization reflects in real life. It is the necessity of developing diversified clothing. It is the true outcome in pursuit of beauty for fashion men.

3) Influenced by family education or birth policy. Since planning the family program in 1983, which has been more than 20 years, because of the only child, in the past, the traditional education of man and woman has changed, not emphasize on the contrast of the strength and status of men and women, pay more attention to cultivating independent personality. Ignoring the factors of family planning, due to the change of the concept of life, the method of children education also has changed, men and women in characters is not like" strong man and weak woman" as usual, men are not as strong as usual by education, on the one hand, it also has played a role in promoting the neutralization of men's wear.

4) The influence of the subculture. In the 20 century $60 \mathrm{~s}, 70 \mathrm{~s}$, rebellion consciousness of youth became thinking foundation of clothing neutralization. For this reason, teenagers in this age are likely to get in rebel line, in pursuit of the freedom on individual body, the thinking liberation. Having courage to express one's individuality, to hate the traditional bondage, personal reaction can involve in men's clothing in this period. Such as diversification, neutralization, feminine... All the forms are amazing by the pursuit of fashion youth. In the 20 century $50 \mathrm{~s}, 60 \mathrm{~s}$, hippie, punk clothing style is a subculture on clothing. This is the product of the trends of against tradition and culture. It shows the split of fashion and the clothing trend of diversification. Neutral clothing embodies the unusual features of the new things. Not only catering to the ideas of needing new and special things for the part of the modern people, but also meeting people's diverse aesthetic demand.

5) The effect of media and celebrity. The development of the men's clothing of neutralization is promoting by the media and celebrity. This young generation has a crush on the clothing dressed by handsome male idols in film and television. So-called "small fresh meat", "metrosexual men" and "South Korean with long legs" no longer have the image of the traditional male traits. Most of them have some weak traits. In 2005, King and the Clown made a hit, the player Lee Jun Ki, to be a household name. The most prominent image is more siren than a woman's. In the early 2006,G-DRAGON as a worldwide famous ICON from the group BIGBANG often worn women's clothing, you can 
feel the unusual flavor. Of course, he also has been named the fashion idol, his fashion is gaining recognition around the world. "Happy big camp" two male hosts is often more partial to neutral clothing to host programs, even the fat DuHai tao often wears very cute clothes like skirts. Feeling like cute girls dressing. Their neutral images appeared in personalized stage frankly, and the young group rushed to follow in their footsteps. So it can be said that the film and television or other medias, celebrity effect also have contributed to the popularity of men's neutral clothing, it can be a powerful factor.

6) The blind herd mentality and imitating effect. In the world of fashion, a large number of neutral characteristics often appear in many clothing shows by famous clothing designers, they have a keen taste for fashion and super control for era, there are a large number of neutral colors designed by people. Their fashion authority promotes the choices of the neutral clothing in the public. On the other hand, men's clothing of neutralization is more expressive and authoritative. In the fashion circle, the men who have special status will usually choose more partial men's clothing of neutralization, this also coincides with the famous designer's designs. Because of the good position in the fashion circle, neutral men's wear is formed to spread and imitate from top to bottom .In order to follow the fashion, the blind herd mentality and imitating is one of the reasons why it has its popularity and people choose it.

7) The attempt and innovation for men's clothing design have got a new bright spot in the direction of men's clothing of neutralization by designers. "Peacock" revolution, let the men's clothing into a colorful era; "Casual Friday", let people begin to abandon the old standard, the trend of the "casual wear". In the social atmosphere of equality of men and women, men begin to be tired of wearing the rigid clothing lines and depressing clothing colors. Be eager to get rid of the framework naturally, to feel comfortable to wear. Designers as promoters for fashion, their roles are not to be ignored. Jealn - Paul Gaultier and Vivienne Westwood as powerful enablers are the most representatives among the designers for men's wear of neutralization. Jealn - Paul Gaultier found the inspiration from the women's clothing, pioneered the men wearing a skirt, also using weird and alternative methods to reverse the aesthetic conceptions in the past. Vivienne Westwood, the British designer, she succeeded in turning the nondominant cultural group's dressing concept into the theme of high fashion. Both designers' ideas were not a simple way to learn from each other, but immersed in a "transcend gender" relationship of neutralization for exploring costumes language. Then neutral clothing became a kind of vivid style. In addition, there are a lot of attempts in the neutralization like international men's clothing brands. Such as Saint Laurent, Armani, Kenzo, Rei Kawakubo and Yohji Yamamoto and so on. Their models mostly are feminine, slender, dressing is not so strong in T stage shows. VERSACEE and Calvin Klein often transform men's clothing into having characteristics of women's clothing in the perspective of gay men. It can arouse the public attention and chase as well as the fashion men.

8) Visual aesthetic changes. The design of men's clothing of neutralization, it has broken the guidelines accepted by traditional dressing group generally. Getting out from the simple style and the boring situation of colors. Diversified styles, colorful clothing are more welcomed by people. People's aesthetics are getting the right way from single to complexity.

\section{The performance of the men's clothing of neutralization in present social phenomenon}

In 2009, "Xiao shenyang" is so famous after the Spring Festival gala, thanks to his neutralization modelling, the Scottish skirt can be said to be the most obvious reason. Zhao Benshan used this good idea according to the current phenomenon of "men love neutralization". Although his idea is ironic and funny, we can see the trend that men's wear of neutralization is so easily tracked.

Brad Pitt in every country of Europe and America has a famous name, thanks to the "butter unripe" image that he played. Brad Pitt has a head of golden hair and clear blue eyes, always with a charming smile, sending out the infinite charm. He not only is the famous Hollywood actor in the world, but also is a Hollywood's most charming man, he is born with untrammeled and romantic characters, or the unique temperament getting out from the body. He is different from previous European and American actor with delicate and capable images, which is the most prominent. Catering to the contemporary people's aesthetics, the path to making his acting is so smooth. After Brad Pitt, Beckham appeared in people's field of vision, he has a healthy image that is full of sunshine. He loves dressing up, paying attention to dressing taste. His wife is the celebrity who we have to mention in the fashion trade. According to above, his movements are in the spotlight.

Now in the most popular Korean influence, mostly star males have rosy lips and pretty white teeth, thinner shape, flavored by fans. Famous G-DRAGON is the representative of the fashion ICON in Korea. He has a sharp taste for garments, known as the star in all stars. He had more than once in the series of women's clothing of CHANNEL. We often see that he is dressing particular clothes with hollowing out, transparent elements. 
In life, it is a common phenomenon that men dressing neutral clothing are walking in every street, you will see many men wearing leggings, or long T-shirt like the dress. Feet pants, pointed shoes, silk shirt, transparent texture clothes, these are easily to see. We are familiar with the men who hit ear hole and wear earrings. From ordinary passers to star performers.

\section{The new characteristics of men's clothing of neutralization}

Neutral features are more obvious and exaggerated. Many famous designers have added skirt elements into their a series of men's clothing, there are also many male performers wearing skirts directly into streets, the impact for sex is far greater than ever.

Wide audience. Like le Bien-Aimé 15 in 18 century, even referred to as "deformity France" because of the painted, well-dressed men and liking women's image. That word also reflected that the trend was not accepted at that age, just belonged to the upper glitterati. In contrast, recently, neutral clothing for people is to be accepted and even deeply rooted in the hearts of the people. Male chauvinism in the present has become a derogatory term. The relatively thin men and " metrosexual men" can be more likely to catch the girls' hearts. It's not hard to see that this trend has been accepted by the public. Men also have the courage to express themselves to gain recognition in their ways.

Broad coverage. In the past the neutralization only embodied in men's clothing and colors, now neutralization trend is leading to a series of peripheral industries. Men watches, handkerchief, skincare products, perfumes, cosmetics, accessories and other products which are related to men, all of them are getting into our eyes. It is no longer limited to the garment industry in the past.

\section{Conclusion}

Although the phenomenon of men's wear of neutralization looks obvious in modern, some men's clothing of neutralization even can be called the feminization of men's wear. It has a long history, it may comply with the trend, is a sign of more delicate male. With the improvement of the social level, men will have more efforts in clothes, men's wear has rejected the previous features of standardization, gender, monotonousness. It tends to neutralization. We believe that men's clothing of neutralization will prevail all over the world.

\section{Acknowledgement}

This project is sponsored by Shanghai University of Engineering Science 2015-year Innovation Fund for Graduate Students.

\section{References}

http://d.wanfangdata.com.cn/Periodical_kxsd201105185.aspx

http://d.wanfangdata.com.cn/Periodical_msjyyj201213049.aspx

Huang Yianmin. (2015). An Analysis On The Phenomena Of Individualization And Neutralization Of Dressing In History From The Point Of Theory Of Level Of Demand (College of Fine Art of Suzhou University, Suzhou 215021).

Li Hui. Zheng ao-jie, Chen Mingzhen. The Research on the Beginning and Changing of Unisex Men's Fashion (Garment School, Wuhan University of Science and Engineering, Wuhan 430073, China).

LiuYu. A Research on the Development and Application of the Style Design of the Neutral Clothing.

Xu Ruixin. Study of androgynous design in modern men's wear.

Zhou Zhengdong. Gender Transgression-study on the neutralization of men's wear. 